sciendo Zagreb International Review of Economics \& Business, Vol. 21, Special Conference Issue, pp. 43-53, 2018 (C) 2018 Faculty of Economics and Business, University of Zagreb and De Gruyter Open

All rights reserved. Printed in Croatia

ISSN 1331-5609; UDC: $33+65$

DOI: 10.2478 /zireb-2018-0023

CONFERENCE PAPER

\title{
Performance Analysis of Fundamentally-Weighted Indices in the Croatian Capital Market
}

\author{
Davor Zoričić* \\ Denis Dolinar* \\ Zrinka Lovretin Golubic *
}

\begin{abstract}
The work of Arnott et al. (2005) presented an interesting fact that the fundamentally-weighted indices generally outperform the market capitalisation-weighted counterparts in the US stock market. The research results prompted the introduction of fundamentally-weighted indices in the US market. Since research dealing with Croatian capital market also points out the inefficiency of the risk return trade-off of the cap-weighted (CROBEX) index this paper examines more closely the risk return characteristics of the potential fundamentally-weighted alternative and analyses the source of higher returns in the case of fundamentally-weighted indices. We use the original and propose a modified Fama French three factor model in order to try to capture specific sources of risk in the small and illiquid market. We find evidence in support of the view that better risk return trade-off of the fundamentally-weighted indices is driven by additional exposure to risk factors in comparison to CROBEX index.
\end{abstract}

Keywords: fundamentally-weighted indices; risk-return trade-off; benchmark efficiency

JEL Classification: $\mathrm{G} 11, \mathrm{G} 12$

\section{Introduction}

The work of Arnott et al. (2005) provided evidence that fundamentally-weighted indices outperform the market capitalisation-weighted indices in the US stock market. Coupled with growing evidence of mean-variance inefficiency of cap-weighted indices (see Amenc et al. (2006) for a comprehensive overview for the developed markets) research findings stimulated index providers to increase the number of fundamental-

* Davor Zoričić, Denis Dolinar and Zrinka Lovretin Golubić are at University of Zagreb, Faculty of Economics and Business, Zagreb, Croatia. 
ly-weighted indices. However, as shown in Amenc et al. (2008a) concerns have been raised regarding views that such indices either implicitly or explicitly rely on valuation inputs making them comparable to active management investment strategies while on the other hand their relation to the mean-variance efficiency remained unclear.

Regarding the Croatian stock market, the same cap-weighted index mean-variance inefficiency is documented in the work of Zoričić (2014) and Habibović (2017). Nevertheless, as presented in Zoričić (2014) and Dolinar (2017) it is much more difficult to outperform the cap-weighted benchmark-CROBEX. Unlike in the developed markets, the naïve equally-weighted strategy performs poorly and as demonstrated in Kovačević et al. (2017) only in the case of one fundamentally-weighted index evidence of superior risk adjusted performance relative to CROBEX was found in an out-of-sample estimation. Moreover, apart from providing evidence of outperformance over the broad based CROBEX index, the research also points out that the increase in return is associated with an increase in volatility relative to the cap-weighted benchmark.

Therefore, in this paper following the work of Kovačević et al. (2017) we focus on the fundamentally-weighted index based on the EBITDA fundamental indicator and adopt the methodological framework of Amenc et al. (2008b) to conduct further analysis based on the issues raised in Amenc et al. (2008a). Thus, in order to analyse the source of higher returns in the case of fundamentally-weighted index we test statistical significance of alfa coefficient in the Sharpe's single index model but also attempt to apply the Fama-French three factor model in search of evidence of additional exposure to risk factors.

Even though Amenc et al. (2008b) report significant size and value tilts in most fundamentally-weighted indices examined, bearing in mind specifics of Croatian stock market and based on the research by Dolinar (2015), we propose a modification to the original Fama-French three factor model by introducing the fourth factor - liquidity, to the multifactor framework.

In the next section of the paper we describe the data sample, the construction of the fundamentally-weighted index analysed and the factor models used in the analysis. Special attention is devoted to the application of the Fama-French multifactor model in the undeveloped market setting. Research findings provide descriptive statistics first, followed by the regression analysis results related to the factor models after which conclusions are drawn in the final section.

\section{Methodology and Data}

\section{Data and Data Sources}

Like most of the research carried out for the Croatian capital market, this one also relies on the CROBEX index which is the oldest and largest index in the Croatian 
financial market. The research covers the period from March $23^{\text {rd }}, 2009$, which is the beginning of the CROBEX index' first regular revision in 2009 , till September $16^{\text {th }}$, 2016, which is the end of the first regular revision in 2016. This means that total of 15 regular revisions were carried out in the observed period. The number of constituents of CROBEX index varied from 23 to 25 stocks (with average of 24) in the whole observed period.

For this research stock prices were downloaded from the Zagreb Stock Exchange (ZSE) which also served as a source of data on book values of equity since they were extracted from companies' annual financial statements (audited and consolidated if available) made available on the ZSE's web pages. Data on the number of shares and dividends per share for the companies were provided by the Central Depository \& Clearing Company Inc. (CDCC). Three-month Croatian Treasury bill rates at the moment of issuing were downloaded from the web page of the Ministry of Finance of Croatia and were used as a proxy for the risk free rate.

Construction of EBITDA Fundamentally-weighted Index for the Croatian Stock Market

Fundamentally-weighted indices in Kovačević et al. (2017) used the same composition as the CROBEX index for each revision in order to compare their performance to the CROBEX benchmark. Out-of-sample performance was analysed and the only index which succeeded to outperform CROBEX index was fundamentally-weighted index based on EBITDA with restriction imposed on the maximum weight of each constituent. Building further on the mentioned research in this paper we focus on that index in order to analyse the sources of its higher returns which facilitate the outperformance.

In Kovačević et al. (2017) weights of each stock in fundamentally-weighted index were calculated based on 3-year average of a fundamental indicator (for preceding 3 years) - in this case EBITDA. In case of a negative value of a fundamental indicator, assigned weight to the constituent was set to zero in order to account for the fact that short selling is not allowed in the Croatian stock market. In order to achieve greater portfolio deconcentration, restriction on maximum weight of a constituent was introduced by setting the limit equal to $\lambda / \mathrm{N}$, where $\mathrm{N}$ is the number of constituents in each revision and $\lambda$ is an arbitrary parameter which was set to $5 .^{1}$ Thus, the maximum weight of a stock in the fundamentally-weighted index was restricted to $20 \%-25 \%$ depending on the number of constituents in a revision.

In this research for the fundamentally-weighted index described above we calculate the excess return (above risk-free rate) on monthly basis in the analysed period (March 2009 - September 2016). ${ }^{2}$ Thus, a time series of 90 monthly returns is obtained. Also, it has to be pointed out that for the purpose of the analysis in this 
paper monthly (total) excess returns were calculated and used for the CROBEX index (based on the CROBEX index weights for each revision), too.

\section{Methodology of Risk-return Analysis of the EBITDA Fundamentally-weighted Index}

Following the work of Arnott et al. (2005) and Amenc et al. (2008b) in order to assess the risk-return characteristics of the fundamentally-weighted portfolio in relation to the CROBEX index we use single and multifactor models in order to thoroughly examine the potential sources of outperformance using different frameworks. We begin with the Sharpe's (1963) single-index market model (a common proxy for the CAPM; equation 1). Afterwards we apply standard Fama-French (1993) three-factor model the implementation of which is slightly adjusted to better suit Croatian equity market (equation 2) with the aim to try to capture additional sources of rewarded risk in small and undervalued companies. In the end we extend the Fama-French (1993) three factor model by adding the fourth risk factor as suggested by Dolinar (2015) for the illiquid Croatian stock market. Therefore, liquidity is added to the model (equation 3).

$$
\begin{gathered}
E\left(R_{i}\right)-R_{f}=b_{i}\left[E\left(R_{M}\right)-R_{f}\right] \\
E\left(R_{i}\right)-R_{f}=b_{i}\left[E\left(R_{M}\right)-R_{f}\right]+s_{i} E(S M B)+h_{i} E(H M L) \\
E\left(R_{i}\right)-R_{f}=b_{i}\left[E\left(R_{M}\right)-R_{f}\right]+s_{i} E(S M B)+h_{i} E(H M L)+l_{i} E(L I Q)
\end{gathered}
$$

Here $\left[\mathrm{E}\left(\mathrm{R}_{\mathrm{i}}\right)-\mathrm{R}_{\mathrm{f}}\right]$ represents expected total return on a stock $i$ in excess of risk-free rate, $\left[E\left(R_{i}\right)-R_{M}\right]$ represents expected total return on a market index (portfolio) in excess of risk-free rate, SMB represents the risk premium related to the company size, HML represents the risk premium related to the company valuation, LIQ represents the risk premium related to the stock liqudity and $b_{i}, s_{i}, h_{i}$, and $l_{i}$ represent sensitives (i.e. exposures or factor betas) to the corresponding variables (i.e. risk factors).

Like in Fama and French (1993), this paper also uses monthly stock returns. In this paper, however, we only consider stocks which are CROBEX index constituents in the analysed period from March 2009 until September 2016. Variables (SMB, HML and LIQ) rebalancing is done on semi-annual basis - every year at the end of March and September, in order to correspond with the CROBEX index revisions.

The definition of Fama-French size and value factors (variables) also deserves a brief description. Company size is a market value of equity at the end of March and September (i.e., to be more precise, at the start of each CROBEX index revisions). $\mathrm{B} / \mathrm{M}$ ratio is defined as book value of equity (at the end of December of year $\mathrm{t}-1$ ) divided by market value of equity (at the start of each CROBEX index revisions). 
In order to obtain time-series of Fama-French model variables, calculation methodology was somewhat changed (adjusted in relation to the original Fama and French (1993) paper). ${ }^{3}$ At start of each CROBEX revision (in March and September of each year from 2009 till 2016), based on the above defined company size and B/M ratio, all stocks that were constituents of the CROBEX index at the time were split: (1) into two groups by size - small vs big ( $\mathrm{S}$ vs B), and (2) into two groups by B/M - high vs low $(\mathrm{H}$ vs $\mathrm{L}){ }^{4}$

Similarly, in order to obtain the time-series of additional (fourth) variable, at the start of each CROBEX revision, all stocks that were constituents of the CROBEX index at the time were split into two groups by liquidity - illiquid vs liquid (ILQ vs LQ). Here we measured liquidity as the quotient of the number of stock traded during the time of previous revision and the total number of stock of a company at the start of current revision.

For all three risk factors (size, $\mathrm{B} / \mathrm{M}$ and liquidity) splitting criteria was the median. Those six overlapping groups of stocks (S, B, H, L, ILQ and LQ) represent portfolios with different fundamental exposures. Time-series of monthly returns of the six portfolios were calculated using equal weights from April to September of year $t$ and from October of year $t$ to March of year $t+1$ (for the whole observed period). We used median as sorting criteria, allowed overlap of above portfolios and applied equally weighting scheme due to the modest number of stocks that were available for valid analysis and because we wanted to eliminate effects of specific risk (return) of large capitalisation stocks which would dominate a small cap-weighted portfolio.

Finally, factor model variables should mimic the underlying risk factors, i.e. should incorporate economic fundamentals into the model. Definitions of model variables used in the context of this paper are given below.

EMR variable, or excess market return, is a proxy for the market factor in stock returns. It is calculated as a monthly return above risk-free rate on the equally-weighted portfolio of the CROBEX index constituents (stocks) at the time.

SMB variable is defined to mimic the risk factor in returns related to company size. It is the difference between the monthly returns on the small-stock portfolio $\mathrm{S}$ and the big-stock portfolio B.

HML variable is defined to mimic the risk factor in returns related to company valuation (B/M ratio). It is the difference between the monthly returns on the highstock portfolio $\mathrm{H}$ and the low-stock portfolio $\mathrm{L}$.

LIQ variable is defined to mimic the risk factor in returns related to liquidity of stocks. It is the difference between the monthly returns on the less liquid stock portfolio ILQ and more liquid stock portfolio LQ.

ER_FWP, or excess (total) return of the previously described fundamentally-weighted (EBITDA) portfolio, is a dependent variable in the used models, i.e. a variable to be analysed in relation to the above defined risk factors and the CROBEX index. 
ER_CROBEX, or excess (total) return of the CROBEX index, is also dependent variable in the used models, i.e. a variable which is used as a common benchmark when investing in Croatian stocks.

Risk-return comparison of the EBITDA fundamentally-weighted index and the CROBEX index is based on the time-series regressions. The slopes (parameters) and $\mathrm{R}^{2}$ values are direct evidence of common variation in returns, i.e. evidence of exposures to the various factors of systematic risk.

\section{Research Findings}

\section{Descriptive Statistics}

After obtaining time series of 90 monthly returns for fundamentally-weighted index, we compare it to the market cap-weighted counterpart as described in previous section.

Figure 1: Comparison of monthly excess returns between fundamentally-weighted index and CROBEX index

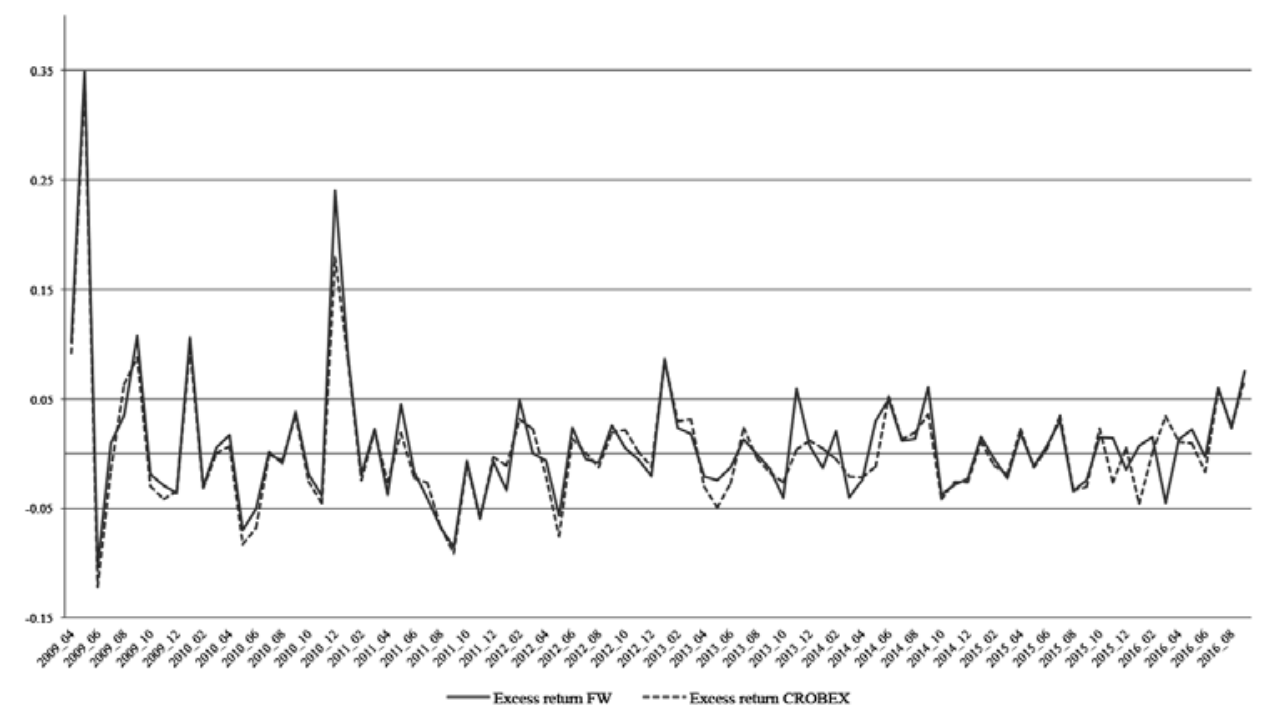

Source: Authors' calculation 
As depicted in Figure 1, monthly excess return for fundamentally-weighted index demonstrates superiority in most months compared to CROBEX index which means that results of analysis by Kovačević et al. (2017) are confirmed on monthly basis as well (in Kovačević et al. (2017) semi-annual returns were used).

Table 1: Average return, risk (volatility) and Sharpe ratio

\begin{tabular}{|l|c|c|}
\hline & Fundamentally-weighted index & CROBEX \\
\hline Average return & 0.00729 & 0.00305 \\
\hline Risk (volatility) & 0.05980 & 0.05696 \\
\hline Sharpe ratio & 0.12183 & 0.05362 \\
\hline
\end{tabular}

Source: Authors' calculation

The data in Table 1 also corroborate the results pointed out by Kovačević et al. (2017). Namely, fundamentally-weighted index achieved higher return compared to the CROBEX index resulting in a higher Sharpe ratio but the increase in return was accompanied by an increase in risk (albeit of a smaller intensity). Furthermore, like in Amenc et al. (2008b), correlation coefficient between the two indices was very high standing at 0.9524 and the t-test revealed a high p-value of 0.817 indicating a lack of statistically significant difference in returns. ${ }^{5}$

The presented results blur the difference between the two portfolios. Namely, the correlation coefficient suggests the two are practically the same in the analysed period. Furthermore, even though the fundamentally-weighted index can boast the higher Sharpe ratio it is based on the higher return but the difference in returns doesn't seem to be statistically significant. As in Amenc et al. (2008a) and Amenc et al. (2008b) such results could suggest no fundamental differences but rather exposure to additional risk factors similar to investment tilts which can be compared to active management strategies. Most importantly, although the main criticism of the cap-weighted indices is lack of (proper) diversification, there is not much evidence in favor of stronger diversification effect in case of the fundamentally-weighted index. Nevertheless, in order to arrive at valid conclusions, the views stated above have to be tested further. We, therefore conduct the proposed analysis using the factor models in an attempt to capture the sources of their performance.

\section{Regression Analysis}

By inputting the abbreviations for variables in the models (all described in the previous sections) the following set of equations is obtained: 


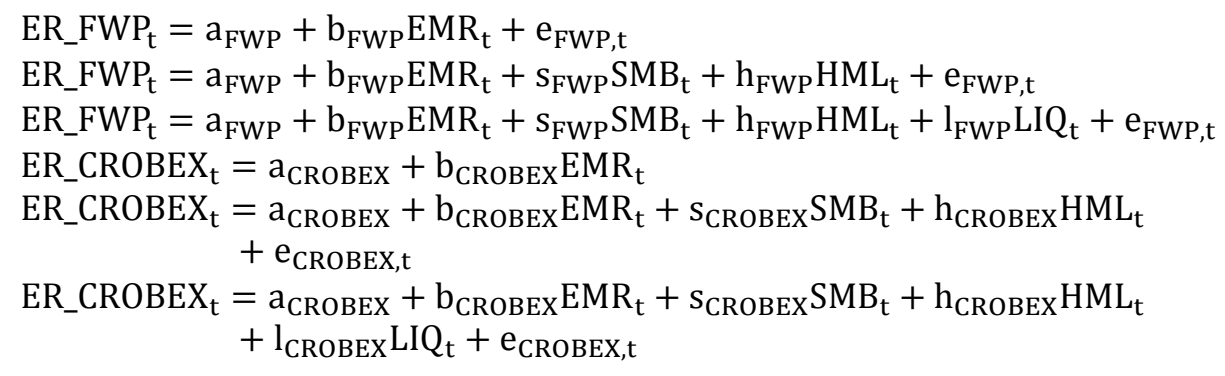

Equations (4)-(6) test fundamentally-weighted index in the three proposed models (Sharpe's single index market model, Fama-French three factor and Fama-French four factor model, respectively) while equations (7)-(9) do the same for the CROBEX index. The regression results are presented in Tables 2 and 3 for each analysed index separately.

Table 2: Regression results for the fundamentally-weighted (EBITDA) index

\begin{tabular}{|c|c|c|c|c|c|c|}
\hline Equation & $\mathrm{a}_{\mathrm{FWP}}$ & $\mathrm{b}_{\mathrm{FWP}}$ & $\mathrm{S}_{\mathrm{FWP}}$ & $\mathrm{h}_{\mathrm{FWP}}$ & $\mathrm{l}_{\mathrm{FWP}}$ & $\mathrm{R}^{2}$ \\
\hline 4 & $0.0057 * *$ & $0.7898^{*} * *$ & - & - & - & $86.15 \%$ \\
\hline 5 & 0.0020 & $0.9524 * * *$ & $-0.3308 * * *$ & 0.0030 & - & $89.93 \%$ \\
\hline 6 & 0.0013 & $0.9643 * * *$ & $-0.1927 * *$ & 0.0217 & $0.2206 * * *$ & $90.76 \%$ \\
\hline
\end{tabular}

Source: Authors' calculation (note: single, double and triple asterisks denote $10 \%, 5 \%$ and $1 \%$ levels of significance respectively).

The determination coefficient is high for both indices and for all three models analysed. Slight difference (which is similar for all three models) in the favor of the CROBEX index can be attributed to the fact that the CROBEX index probably resembles more closely (exhibits less tilts in weights) the equally-weighted portfolio used as a proxy for the market portfolio in the analysis.

By further comparing the results in Tables 2 and 3 one can notice that alfa $\left(\mathrm{a}_{\mathrm{FWP}}\right)$ coefficient is statistically significant in the single index model for the fundamentally-weighted (EBITDA) index as opposed to the same parameter in the case of the CROBEX index $\left(\mathrm{a}_{\mathrm{CROBEX}}\right)$. If one was convinced that such factor model is valid (well specified), the higher value of intercept could be interpreted as superior risk adjusted performance of the observed portfolio or index.

Table 3: Regression results for the CROBEX index

\begin{tabular}{|c|c|c|c|c|c|c|}
\hline Equation & $\mathrm{a}_{\text {CROBEX }}$ & $\mathrm{b}_{\text {CROBEX }}$ & $\mathrm{s}_{\text {CROBEX }}$ & $\mathrm{h}_{\text {CROBEX }}$ & $\mathrm{l}_{\text {CROBEX }}$ & $\mathrm{R}^{2}$ \\
\hline 7 & 0.0015 & $0.7807^{* * *}$ & - & - & - & $92.75 \%$ \\
\hline 8 & -0.0017 & $0.9281^{* * *}$ & $-0.2856^{* * *}$ & -0.0216 & - & $96.04 \%$ \\
\hline 9 & -0.0020 & $0.9331^{* * *}$ & $-0.2269^{* * *}$ & -0.0137 & $0.0937 *$ & $96.20 \%$ \\
\hline
\end{tabular}

Source: Authors' calculation (note: single, double and triple asterisks denote $10 \%, 5 \%$ and $1 \%$ levels of significance respectively). 
However, as argued in Fama and French (1996) the cross section of returns is usually better explained using a multifactor model in which suddenly the same coefficient is not statistically significant regardless of the analysed index or the specified model. The finding implies that the sources of potential superior performance of the fundamentally-weighted (EBITDA) index (in the single index model) are revealed in the form of additional risk factors in the multifactor model framework.

The variable EMR as the market factor and the variable SMB related to company size seem to be statistically significant in both three factor and four factor models for both indices while the HML variable related to the company value seems to be statistically insignificant regardless of the model or index. It can be noticed that the mentioned statistically significant variables seem to influence the analysed indices in the same direction and with approximately same intensity across the models. Regarding the SMB variable it should be noted that negative value of the estimated coefficient has to be considered bearing in mind that the difference between the monthly returns on the small-stock portfolio $S$ and the big-stock portfolio $B$ was negative in the analysed period. This implies that in the Croatian stock market investing in big companies pays a premium and negative SMB coefficient values suggest a size tilt towards big companies in both indices.

Finally, most importantly what sets the analysed indices in the performed analysis apart is the LIQ variable related to stocks' liquidity. Estimated coefficients regarding this variable are statistically significant for both indices (although in the case of a fundamentally-weighted index at a higher, $1 \%$ level) but the higher value of $1_{\text {FWP }}$ suggests a significant factor tilt revealing that the major source of additional increase in return is arising from this additional risk exposure. Therefore, the obtained results suggest that it is dominantly due to additional exposure to liquidity risk factor (i.e. through additional risk taking) that fundamentally-weighted index earns greater returns which are, not surprisingly, also accompanied by an increase in volatility (i.e. risk to investor).

\section{Conclusion}

Motivated by the research providing evidence of the market cap-weighted index inefficiency and the superior risk adjusted performance of the fundamentally-weighted index alternatives this paper provides an analysis of the sources of outperformance of fundamentally-weighted alternative in the Croatian stock market. The main finding of the performed analysis is that the outperformance does not arise from an increase in portfolio diversification but rather, from the quite opposite source, exposure to additional risk factor.

In the paper by Kovačević et al. (2017) a fundamentally-weighted index based on EBITDA fundamental indicator was found to outperform the CROBEX index but 
issues concerning the source of outperformance were raised as evidence of not only higher return but also higher risk (volatility) relative to the cap-weighted benchmark were reported. Such concerns complemented the views reported in Amenc et al. (2008a) which were tested in Amenc et al. (2008b). Our study confirms the main findings of Amenc et al. (2008b) in the case of illiquid and undeveloped Croatian stock market by showing the high correlation between the two analysed indices and by corroborating the view that fundamentally-weighted index creates exposure to additional risk factor similar to investment tilt which can be associated with active management strategies. However, unlike for the developed markets, for the Croatian stock market we do not find pronounced size or value tilt, but provide evidence of exposure to liquidity factor (premium for illiquid stocks).

Therefore, in this study we provide evidence in support of the view that superior performance related to fundamental weighing leads to exposure to additional risk factors even in undeveloped markets when specific risk factors are taken into account. Thus, such strategies lead to implicit factor tilts similar to active management strategies which should be revealed to investors. There does not seem to be any evidence of an increase in the diversification effect relative to the cap-weighted benchmark.

The main shortcomings of this paper are related to the undeveloped market resulting in a few stocks in portfolios based on which size, value and liquidity premiums are determined in the three factor and four factor model. Also, beginning in the March 2009, the analysed sample does not include a period of expansion of the Croatian economy which should be taken into account in the future. On the other hand, based on the reported findings and since it is generally unclear how fundamentally weighted indices could be related to the optimal - maximum Sharpe ratio portfolio, this research strand is probably unlikely to be pursued unless related to an active portfolio management view.

\section{ENDNOTES}

1 Such portfolio deconcentration approach was pursued following the work of Amenc et al. (2011).

2 Kovačević et al. (2017) matched the constitution of the fundamentally-weighted indices and of the CROBEX index but measured the performance based on semi-annual out-of-sample returns (from one CROBEX revision period to another). Bearing in mind the scope of our research in this paper we use the same approach but change data frequency to monthly in order to obtain a richer time series containing more observations.

3 For instance, Fama and French (1993) rebalance their portfolio on a yearly basis. They took June as the month for mimicking portfolio construction. Also, they did not use median when separating high and low $\mathrm{B} / \mathrm{M}$ stocks. There are other methodological differences too, which we do not discuss in detail for the sake of brevity as they are mostly related to necessary or practical adjustments regarding the small number of stocks in the undeveloped markets. 
4 Thus, we rebalance each variable (portfolio) 15 times, since there were 15 regular revisions of the CROBEX index during observed period (i.e. we start with the first revision of 2009 and end with first revision of 2016).

5 Amenc et al. (2008b) report statistically significant difference in returns over S\&P500 cap-weighted index only in the case of 3 out of 14 tested fundamentally-weighted indices.

\section{REFERENCES}

Amenc, N., Goltz, F. \& Le Sourd, V. (2006). Assessing the Quality of Stock Market Indices: Requirements for Asset Allocation and Performance Measurement. Nice, France: An EDHEC Risk \& Asset Management Research Centre Publication.

Amenc, N., Goltz, F. \& Le Sourd, V. (2008a). Fundamental Differences? Comparing Alternative Index Weighting Mechanisms. Nice, France: An EDHEC Risk and Asset Management Research Centre Publication.

Amenc, N., Goltz, F. \& Le Sourd, V. (2008b). A Comparison of Fundamentally Weighted Indices: Overview and Performance Analysis. Nice, France: EDHEC Risk and Asset Management Research Centre.

Amenc, N., Goltz, F., Martellini, L. \& Retkowsky, P. (2011). Efficient Indexation: An Alternative to Cap-Weighted Indices. The Journal of Investment Management. 9(4), 1-23.

Arnott, R., Hsu, J. \& Moore, P. (2005). Fundamental Indexation. Financial Analysts Journal. 61(2), 83-99.

Dolinar, D. (2015). Identifikacija faktora sistematskoga rizika i mogućnost primjene faktorskih modela na hrvatskom dioničkom tržištu. Doctoral Thesis, Faculty of Economics and Business Zagreb.

Dolinar, D., Zoričić, D. \& Kožul, A. (2017). Towards the Estimation of an Efficient Benchmark Portfolio: The Case of Croatian Emerging Market. Zagreb International Review of Economics \& Business. 20(s1), 13-23. DOI: 10.1515/zireb-2017-0002.

Fama, E. F. \& French, K. R. (1993). Common Risk Factors in the Returns on Stocks and Bonds. Journal of Financial Economics. 33(1), 3-56. DOI: 10.1016/0304-405X(93)90023-5

Fama, E. F. \& French, K. R. (1996). Multifactor Explanations of Asset Pricing Anomalies. Journal of Finance. 51(1), 55-84. DOI: 10.1111/j.1540-6261.1996.tb05202.x

Habibović, A., Zoričić, D. \& Lovretin Golubić, Z. (2017). Efficiency of CROBEX and CROBEX10 stock market indices. UTMS Journal of Economics. 8(3), 271-280.

Kovačević, M., Zoričić, D. \& Lovretin Golubić, Z. (2017). Primjena indeksa temeljenih na fundamentalnim pokazateljima na hrvatskom tržištu kapitala. Zbornik Ekonomskog fakulteta $u$ Zagrebu. 15(2), 29-44. DOI: 10.22598/zefzg.2017.2.29

Sharpe, W. F. (1963). A Simplified Model for Portfolio Analysis. Management Science. 9(2), 277-293. DOI: $10.1287 / \mathrm{mnsc} .9 .2 .277$

Zoričić, D., Dolinar, D. \& Kožul, A. (2014). The Market Index Benchmark and Adequate Compensation for Systematic Risk in an Illiquid and Undeveloped Financial Market. In D. Miloš Sprčić (Eds.), Risk Management: Strategies for Economic Development and Challenges in the Financial System (pp. 257-277). New York, USA: Nova Science Publishers, Inc. 